TRABAJOS DE PREHISTORIA

$51,{ }^{\circ}{ }^{\circ} 2,1994$, pp. $149-158$

\section{LA VENUS DE GAVÀ (BARCELONA). UNA APORTACIÓN FUNDAMENTAL PARA EL ESTUDIO DE LA RELIGIÓN NEOLÍTICA DEL SUROESTE EUROPEO}

THE VENUS OF GAVÀ (BARCELONA).

A BASIC CONTRIBUTION TO THE

STUDY OF NEOLITHIC RELIGION

IN SOUTHWESTERN EUROPE

JOSEP BOSCH ARGILAGOS (*)

ALICIA ESTRADA MARTIN (*)

\section{RESUMEN}

Las excavaciones arqueológicas en las Minas Prehistóricas de Gavà (Barcelona), explotadas durante el neolítico, han puesto al descubierto recientemente en el interior de uno de sus pozos la Venus de Gavà. Es una figura antropomorfa femenina de cerámica, sobre la que se han dibujado las partes del cuerpo y su ornamentación mediante decoración en relieve y esgrafiada con pintura blanca incrustada. Es la única figura humana del Neolítico de la Península Ibérica con una morfología y motivos decorativos que permiten suponerle un valor religioso relacionado con el culto a la diosa de la fertilidad.

\begin{abstract}
The "Venus" of Gava has been recently found in one of the shafts of the archaeological excavation at the Prehistoric Mines of Gavà (Barcelona), exploited in the neolithic period. It is an anthropomorfic feminine ceramic figure whose body and garments are drawn in relief and incised with white paint. It is the only human figure from the Neolithic period in the Iberian Peninsula whose
\end{abstract}

(*) Museo de Gavà. Plaza Dolors Clua 13-14. 08850 Gavà. Barcelona.

El artículo fue remitido en su versión final el 31-X-94. morphology and decorations can intail a religious value related to the goddess of fertility worship.

Palabras clave: Minas Prehistóricas de Gavà. Variscita. Figura humana femenina de cerámica. Religión. Diosa de la fertilidad. Neolítico Medio. Chasense.

Clue words: Prehistoric Mines of Gavà. Anthropomorfic feminine ceramic figure. Religion. Goddess of fertility. Middle neolithic. Chasséen.

\section{INTRODUCCIÓN}

La figura que estudiamos en este artículo procede del yacimiento arqueológico de las $\mathrm{Mi}$ nas Prehistóricas de Gavà (Barcelona), situado en la vertiente marítima de la Cordillera Litoral Catalana, sobre uno de los contrafuertes del macizo del Garraf, al sur de la desembocadura del río Llobregat. Se trata de las minas subterráneas en galería más antiguas de Europa. El yacimiento fue descubierto como tal en la década de los años $70 \mathrm{y}$ desde entonces ha sido 

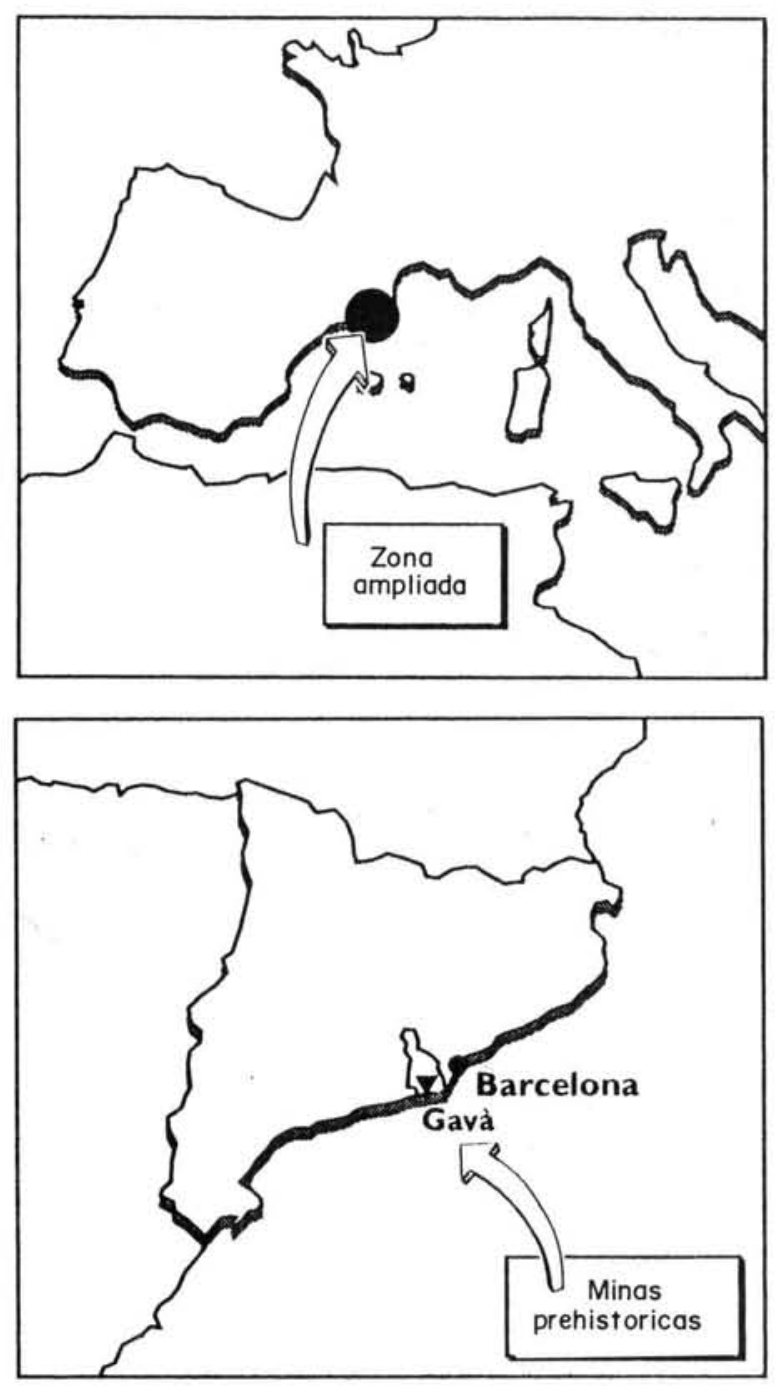

Fig. 1. Situación de las minas neolíticas de Gavà (Barcelona) en la Península Ibérica y en Cataluña.

objeto de diferentes estudios (Villalba et alii, 1986) (Fig. 1)

Ya desde su descubrimiento se reconoció como una explotación minera del Neolítico Medio, dentro del horizonte cultural de los Sepulcros de Fosa. Los minerales extraídos debieron ser varios, utilizados tanto para la fabricación de útiles como de ornamentos, destacando por su singularidad la variscita. Las intervenciones arqueológicas realizadas han sido numerosas, así como los estudios derivados de éstas, si bien quedan aún cuestiones por aclarar. Aspectos como cuáles fueron los recursos explotados y la importancia de cada uno de ellos, las fases de la explotación y su cronología o el significado del complejo minero dentro del contexto económico, social y cultural de su época, no se conocen de una forma plena. A todo ésto había que añadir los problemas de conservación que presenta el yacimiento, así como la escasa difusión a nivel divulgativo de los resultados de las diferentes investigaciones (Lám. I).

En el año 1991, desde el Museo de Gavà, se inició un proyecto integral sobre el yacimiento. Los objetivos del proyecto eran: desarrollar una actuación global que contemplase su conservación, estudio y difusión tanto a nivel científico como general. La complejidad del yacimiento requería una intervención interdisciplinar, por lo que se establecieron convenios con diferentes universidades para formar el equipo necesario: Facultad de Geología de la Universidad de Barcelona y Escuela Universitaria de Ingeniería de Minas de Manresa de la Universidad Politécnica de Cataluña.

La actuación arqueológica en el propio yacimiento es fundamental dentro del Proyecto $\mathrm{Mi}$ nas Prehistóricas. Desde su puesta en marcha se ha intervenido en varios sectores del mismo, tanto por medio de actuaciones programadas como de excavaciones de urgencia.

\section{DESCRIPCIÓN Y CONTEXTO}

En una de las minas en las que el Museo de Gavà ha efectuado excavaciones dirigidas por los autores de este artículo (la mina $\mathrm{n}^{\circ} 16$ ), aparecieron varios trozos de una figurita antropomorfa de cerámica incompleta (véase portada de la revista) (1), repartidos por diferentes niveles del relleno del pozo. Dicha figurita fue elaborada siguiendo el mismo procedimiento que en un recipiente de cerámica. Su calidad es muy buena. El grosor de la pared es más o menos constante, de unos $5 \mathrm{~mm}$. La pasta presenta los colores negro en la mitad externa y rojo en la interna. El desgrasante visible es mayoritariamente de cuarzo y de un tamaño inferior a 1 $\mathrm{mm}$. El acabado de las paredes interna y externa es bruñido, y su coloración oscura, siendo más negra la externa que la interna (Láms. II y III).

Presenta tres sistemas decorativos distintos: el relieve, el grabado o esgrafiado y el pintado.

(1) El dibujo ha sido expresamente realizado para la portada de Trabajos de Prehistoria. 51, 2, 1994 por Ramón Álvarez.

T. P., $51, n{ }^{\circ} 2,1994$ 


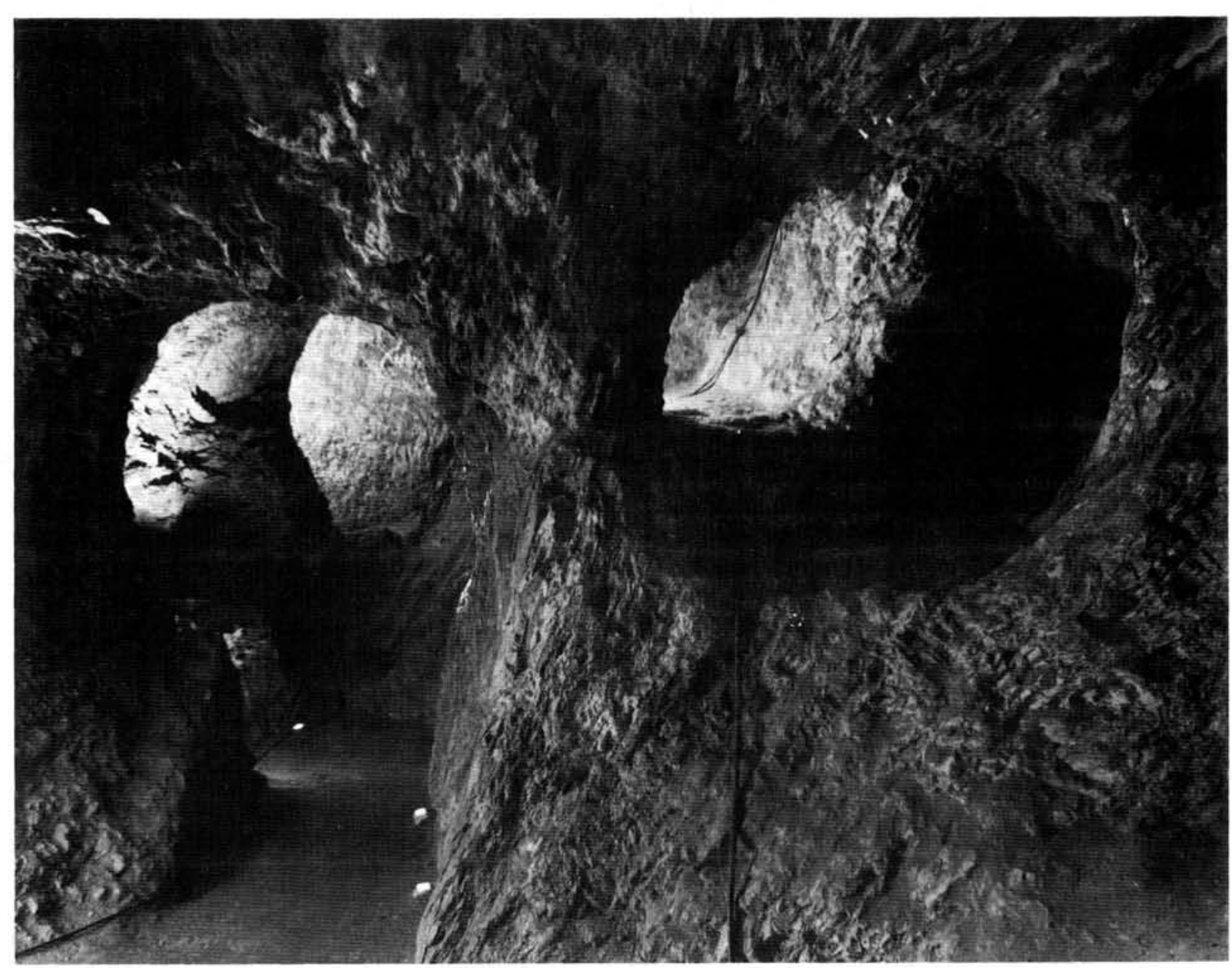

Lám. I. Detalle interior de la mina número 8 del conjunto de las Minas Prehistóricas de Gavà (Barcelona) (Estudio de Fotografía Martín García).

Este último utilizado como complemento del esgrafiado ya que la pintura aparece únicamente incrustada dentro de las líneas grabadas. Esta técnica fue documentada por J. Vaquer (1975) entre la cerámica correspondiente al Chasense del Languedoc. Dichas líneas, una vez practicadas, fueron rellenadas con una pasta blanca, quizás elaborada con conchas de molusco trituradas. No se ha conservado la pintura blanca en toda la extensión de las mismas, aunque posiblemente debieron tenerla. La decoración en relieve aparece en la representación de la nariz, las extremidades superiores y los ojos, mientras que la decoración esgrafiada y pintada se utilizó en la representación de los ornamentos corporales (brazaletes, collar y quizás anillos), del vestuario, de lo que parecen ser las pestañas, y quizás del peinado.
La parte conservada de la figura tiene unas dimensiones de $16 \mathrm{~cm}$ de alto por $11 \mathrm{~cm}$ de ancho. Se distingue la mitad izquierda de la cara y parte de la derecha, el tórax entero, la extremidad superior izquierda completa, buena parte de la derecha, y la parte superior del abdomen.

De la cara parece que únicamente se representaron los ojos y la nariz, obviándose la boca y quizás las orejas. La nariz es alargada, estrecha y de perfil estilizado. Su prominencia decrece progresivamente de la parte inferior, donde presenta los dos orificios, hacia la superior. Los ojos son circulares, representados por una pastilla en relieve poco resaltado, rodeada por una serie de rayos grabados (posibles pestañas), formando en conjunto lo que parece una representación solar.

Por debajo de la cara se encuentra un motivo esgrafiado, que por su forma y situación in- 


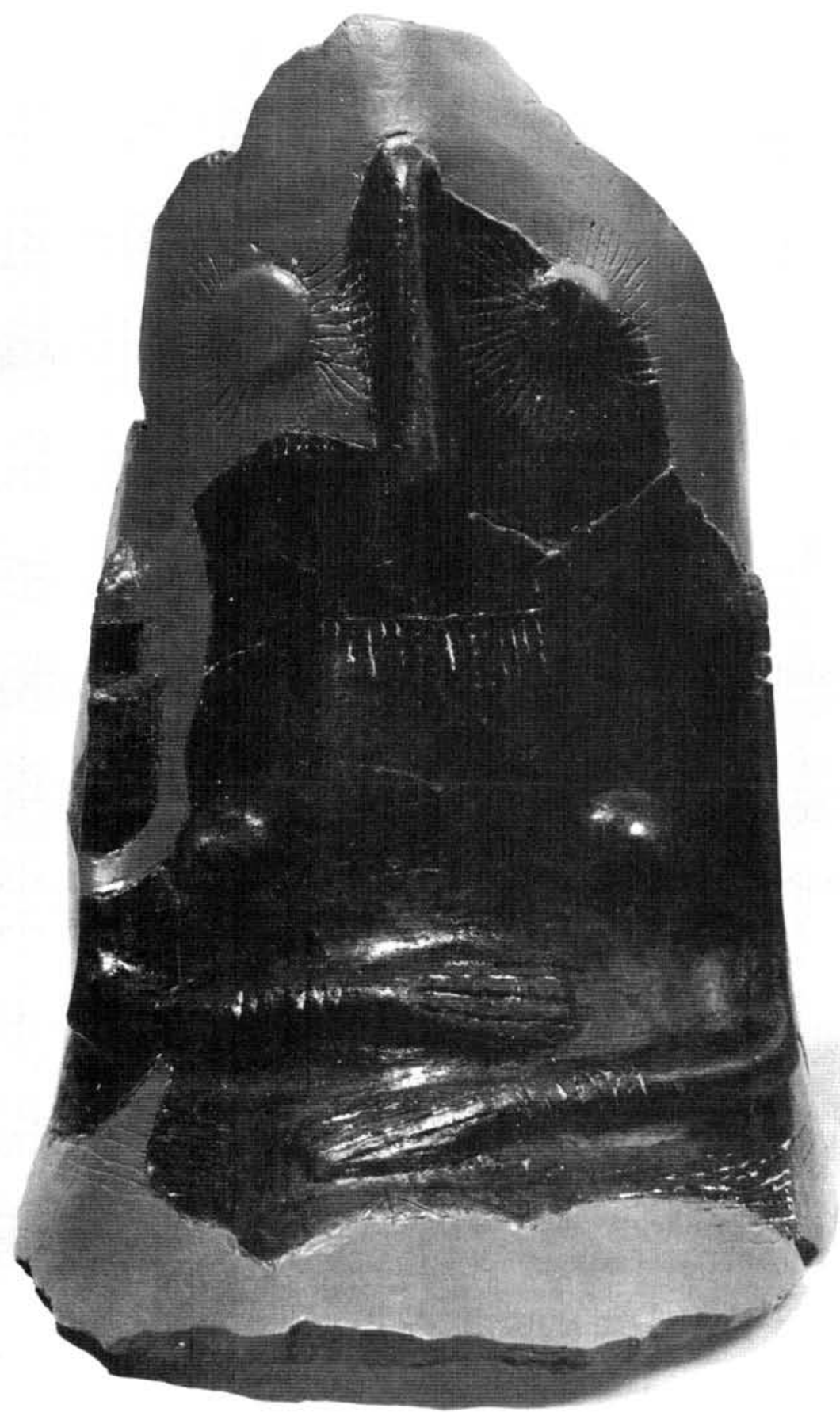

Lám. II. Vista frontal de la Venus de Gavà (Barcelona). Dimensiones 16 × $11 \mathrm{~cm}$ (Estudio de Fotografia Martín García).

T. P.. 51.n. ${ }^{\circ} 2.1994$

(c) Consejo Superior de Investigaciones Científicas 


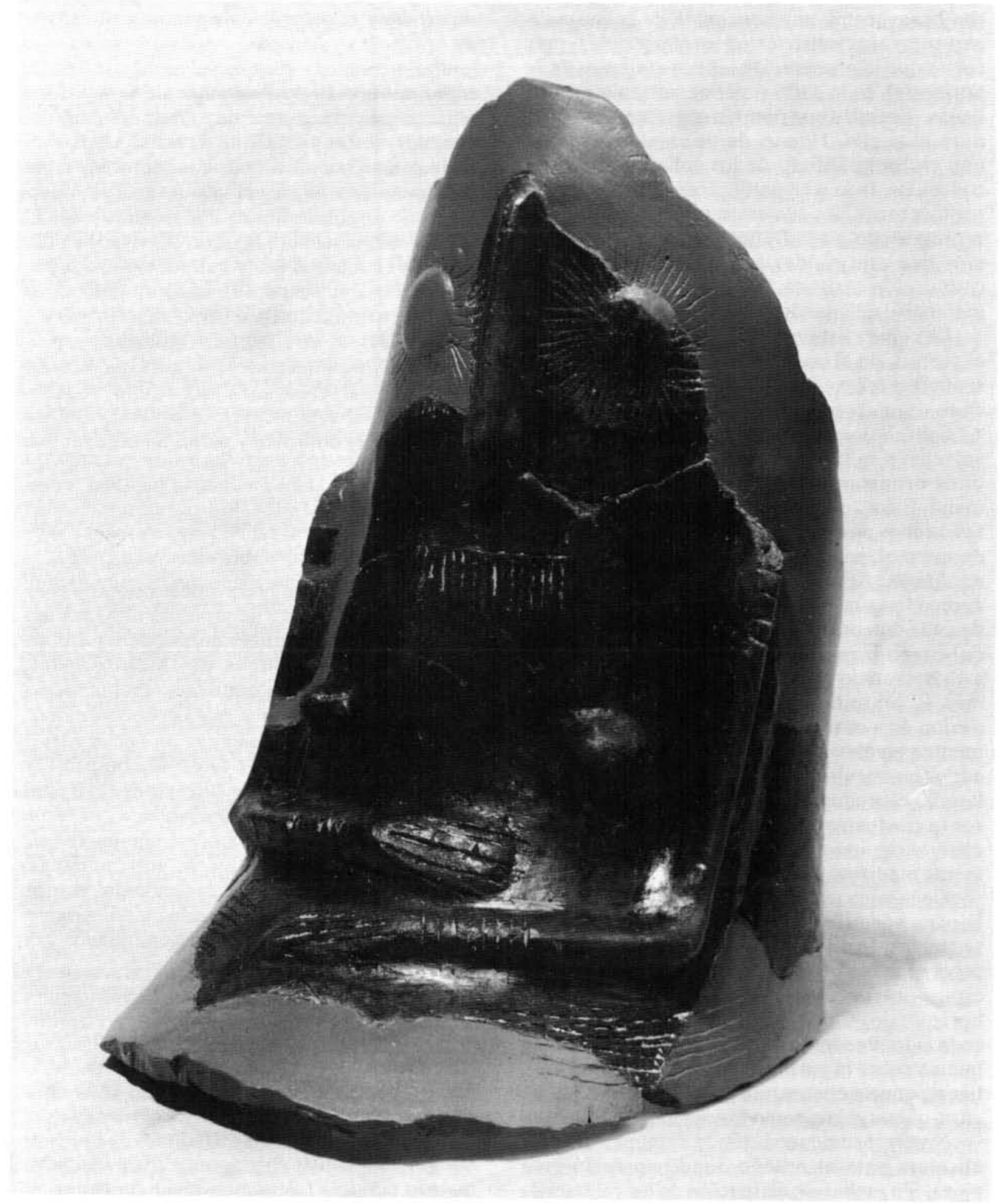

Lám. III. Vista en ángulo de tres cuartos de la Venus de Gavà (Barcelona). Dimensiones $16 \times 11 \mathrm{~cm}$. (Estudio de Fotografía Martín García).

T. P., 51, n. ${ }^{\circ} 2,1994$ 
terpretamos como collar. Está formado por varias líneas rectas: una horizontal, de la que cuelgan otras dieciseis, verticales y paralelas, más cortas que la primera. De los dos extremos de la horizontal, en la parte superior, parten otras dos líneas verticales que podrían representar la ligadura al cuello. Hemos de decir, sin embargo, que el diseño difiere de los collares neolíticos conocidos, la mayor parte procedentes de ajuares funerarios, los cuales no son rígidos como el representado en la figura estudiada. No creemos que esta rigidez sea el resultado de una convención artística. Más bien nos parece un ideomorfo del que desconocemos el significado.

La cabeza está encajada directamente sobre el cuerpo, sin el cuello, y sobre el tórax se representan en relieve circular poco resaltado dos pechos.

Sobre las extremidades superiores también en relieve se grabaron, con cuidadoso detalle, unos ornamentos y los cinco dedos de cada mano. Estos ornamentos recuerdan los brazaletes, hechos de concha de molusco (glycymeris) o de mármol, hallados en numerosos yacimientos neolíticos. Aparecen en las dos extremidades agrupados y paralelos, ocho en la parte inferior de cada antebrazo, y otros cuatro en la superior del brazo izquierdo, si bien como el hombro está fracturado pudieron haber existido algunos más. El brazo derecho no conserva la parte superior. Las extremidades aparecen completamente pegadas al cuerpo, con los codos flexionados en ángulo recto, las manos con los dedos largos, estirados y juntos, descansando planas sobre el vientre. En la mano derecha parecen observarse unos anillos, representados igualmente mediante esgrafiado.

De la zona abdominal se conserva solamente la parte superior, que aparece abultada, como si se tratara de un embarazo. En el centro se observa grabado el extremo de lo que parece una espiga en posición vertical invertida, con líneas horizontales y paralelas también esgrafiadas a cada lado. Pueden representar el vestido (falda), que no cubre la parte superior del cuerpo. Otras líneas, que se encuentran en el costado de la figura, quizás representan los cabellos.

No disponemos todavía de ninguna datación absoluta para el relleno donde apareció esta pieza. Sin embargo, en función de las características técnicas y morfológicas de la misma y de las de otros materiales que proceden del mismo relleno, podemos situarla en el Neolítico Medio.
El acabado bruñido, la coloración oscura de la superficie y la decoración esgrafiada, presentes en la figurita y en otros materiales de su contexto, encuentran sus paralelos más próximos en las culturas de los Sepulcros de Fosa y Chasense. Según el conjunto de dataciones $\mathrm{C} 14$ disponibles para el yacimiento de las Minas Prehistóricas de Gavà, en este yacimiento parece detectarse una fácies cultural postcardial, dentro de la segunda mitad del IV milenio a.C. (cronología no calibrada), que conviviría ya con algunos elementos de la cultura de los Sepulcros de Fosa, la cual acabaría por imponerse en la primera mitad de III milenio a.C. (Bosch Estrada, 1994). A este segundo momento corresponde muy posiblemente la figurita que aquí estudiamos, si bien será necesario esperar dataciones absolutas para el contexto del hallazgo que lo confirmen y permitan precisar más su cronología.

\section{COMENTARIO}

Con el fin de que nos ayude a valorar y comprender el significado de la Venus de Gavà, hemos recopilado un primer corpus de figuras antropomorfas neolíticas del Mediterráneo occidental y regiones limítrofes. Incluimos todos aquellos objetos que puedan ser considerados figuras en un sentido general. Dicho corpus no es exhaustivo, y es un tanto descompensado al incluir piezas de tipos diferentes (material, técnica y forma), correspondientes a contextos y cronologías no necesariamente equiparables.

Si comparamos las figuras antropomorfas neolíticas del Mediterráneo occidental con las balcánicas y próximo orientales, podemos ver como las primeras son menores en número y de una calidad inferior.

En Cataluña y su área más próxima durante el Neolítico únicamente se conocían tres representaciones supuestamente antropomorfas:

- Una placa cruciforme de hueso, de 68 $\mathrm{mm}$ de largo, con dos perforaciones en la parte central encontrada en el yacimiento postcardial de la Timba del Barenys (Riudoms, Tarragona), integrando el ajuar correspondiente a una inhumación múltiple (estructura $\mathrm{n}^{\circ} 1$ ). Su forma sugiere cierto parecido con idolillos de la llamada cultura de Almería (Vilardell, 1992: 117-118). Los huesos humanos han proporcionado una

T. P., 51, n. $^{\circ} 2,1994$ 
datación C 14 de 5240£160 BP (Romero Miró, 1993).

- Un objeto de piedra formado por un cuerpo más o menos elíptico, del que parte una prolongación centrada a manera de mango. Procede del yacimiento también postcardial de Cal Metge (Montmeló, Barcelona), fue hallado en antiguas excavaciones de lo que parecen restos de una estructura de conservación de alimentos en fosa. Sus dimensiones son $88 \mathrm{~mm}$ de largo, $40 \mathrm{~mm}$ de ancho y $16 \mathrm{~mm}$ de grosor. Presenta, no sin dudas, paralelos con los llamados ídolos en forma de "caja de violín", también de la cultura de Almería (Bosch, 1991: 28).

- Un fragmento proximal de segunda falange de ciervo, encontrado en el yacimiento de Botiquería dels Moros (Mazaleón, Bajo Aragón), en el nivel correspondiente al neolítico cardial. Tiene una serie de muescas talladas transversales sobre su arista dorsal y otras incisiones, también paralelas y en la misma orientación. Barandiarán (1978: 98) propone clasificarlo dentro de la categoría de supuestos ídolos.

A la citada cultura de Almería corresponde un conjunto de pequeños objetos considerados ídolos antropomorfos, algunos con atributos femeninos (pechos). Tradicionalmente han sido adscritos al Calcolítico o a los inicios de la Edad del Bronce; sin embargo, hallazgos efectuados en los últimos años permiten que muchos de ellos sean considerados cronológicamente circunscritos al Neolítico Medio y Final (Martí, 1990: 221).

Un número más elevado de figuras ha proporcionado el territorio francés. Por lo que se refiere a las modeladas en arcilla, aparecen repartidos en cuatro zonas: mediodía francés, Macizo Central, zona septentrional y Franco-Condado (Guilaine, 1980: 120-122; Montjardin Roger, 1993: 87-91). A pesar de la simplicidad y la fragmentación de estas figuritas, se puede decir que casi todas corresponden al sexo femenino. A veces tienen representados los pechos, los ojos, la nariz, los brazos y las piernas, nunca las orejas y la boca (Montjardin Roger, 1993: 88). En función de los paralelos disponibles son incluídas por estos autores en una corriente ideológica o religiosa mediterránea. Italia, dada su posición central y abundancia de ejemplares de figuras, debió tener un importante papel en esta corriente (Montjardin Roger, 1993: 90).

También en Francia fué hallada la llamada diosa de Capdenac-le-Haut (Lot), considerada la estatua prehistórica más antigua de dicho país y hasta el momento sin ningún equivalente dentro del Neolítico francés. Fué descubierta y publicada por J. Clottes y M. Carrière (197476), en excavaciones practicadas en un campamento establecido al pie de un abrigo, sobre una terraza que domina desde unos treinta metros el valle de Lot. La ocupación se sitúa hacia el 3000 a.C. Se trata de una pieza esculpida sobre roca, de apariencia rudimentaria y maciza, en la que se representan con caracteres no realistas la cabeza y el tronco. Las dimensiones son: altura $27 \mathrm{~cm}$, ancho de cara $17 \mathrm{~cm}$ y ancho de perfil $25 \mathrm{~cm}$. En la cabeza se distinguen dos ojos redondos en relieve, una nariz muy larga y la boca circular. Está colocada directamente sobre el tronco, de manera que forma una especie de volumen cúbico. Estan representados los pechos y las extremidades superiores, pegadas al cuerpo, con los codos doblados y las manos con únicamente tres dedos sobre el vientre.

Por lo que se refiere a Francia, las últimas figuras neolíticas pueden encontrarse entre las llamadas estelas o estatuas-menhires provenzales en piedra. La cronología de estas figuras en su conjunto no es segura y la mayoría corresponden a descubrimientos antiguos mal documentados. A pesar de ésto algunos fragmentos han sido hallados en sepulturas del neolítico medio o reciente, por lo que algunas se atribuyen a la población del final del IV milenio y la primera mitad del III (Guilaine, 1980: 123-124).

Acostumbran a ser de pequeña talla, alrededor de $30 \mathrm{~cm}$ de alto. Como caracteres generales presentan una cabeza esquematizada y sin cuello, si bien en ocasiones también aparece separada. La cara tiene forma de rectángulo o cuadrado en vacío, abierto por su parte inferior. La nariz en relieve se destaca netamente de este cuadrilátero. Se representan también los brazos y las manos apoyadas sobre el vientre. A menudo los pechos son figurados y lo mismo sucede con un collar. Masculinas, femeninas o indeterminables, extremamente estilizadas, carecen sistemáticamente de boca. Entre las femeninas se constata la exigüidad de los pechos, que parecen únicamente representados para señalar la feminidad de los ídolos. Vestidas con túnica corta, algunas están representadas provistas de armas (arcos, flechas puñales o hachas) (Bordreuil, 1993: 72).

Italia, como ya se ha dicho, ha proporcionado un número elevado de figuras humanas, 
del Neolítico Antiguo y del Medio. Destacamos por sus similitudes en la decoración con la de Gavà algunas pertenecientes al grupo de Gaban, Neolítico Antiguo de Italia septentrional. Este grupo tiene, segun B. Bagolini (1978) afinidades balcano-danubianas. Coinciden en el motivo interpretado como collar, que en las italianas parece un cinturón, y en la espiga del abdomen (Kozlowski, 1990: fig.11.4). Según M. Gimbutas (1989: 103), quien añade a los casos italianos una figurita procedente de Jela (norte de la antigua Yugoslavia), espigas en esta posición están relacionadas con la vulva femenina.

En el sureste de la Península Ibérica, Extremadura y Portugal han sido halladas diversas figuras antropomorfas que se agrupan dentro de la cultura de Los Millares. Se trata de los ídolos elaborados sobre soportes diversos (pequeñas plaquetas de esquisto decoradas, cilindros de mármol o calcárea, cerámicas funerarias y huesos). Su principio básico es la combinación de motivos geométricos con los elementos esenciales para sugerir a la diosa madre. La cabeza se indica por una inflexión poco marcada y, sobre todo, por la representación de los ojos (Åberg, 1921). Estos aparecen a menudo con forma de soles, los cuales presentan un estrecho parecido con los de la figura de Gavà.

Si bien la cronología de la cultura de Los Millares presenta problemas, las dataciones de la fase pre-Millares son escasas y los yacimientos con ídolos fueron excavados de antiguo, el contexto cultural parece distinto al del resto de las figuras citadas, dentro ya de la Edad del Cobre. A partir del principal grupo de fechas absolutas disponibles, la cultura de los Millares aparece comprendida entre el 2400 y el 1800 a.C. (Chapman, 1991: fig.13).

Finalmente, y aunque localizadas fuera del Mediterráneo occidental, hemos de citar las figuritas antropomorfas encontradas en el sureste de Europa, por ser éstas las que presentan un mayor parecido material, técnico, morfológico y decorativo con la figura de Gavà (Srejovic, 1968; Garasanin, 1968; Kalicz, 1970; Gimbutas, 1989 y 1991). Al igual que las del Neolítico sirio-palestino donde, a partir de los milenios VI y $\mathrm{V}$, la figura de la diosa madre pasa a un primer plano. Está representada generalmente sentada, algunas veces con los rasgos de la cara deformados y en muchas ocasiones embarazada. La expansión de este tema va ligada a la de la agricultura y la sedentarización, aunque no por ello se debió tratar únicamente de una divinidad agrícola (Cauvin, 1972).

A pesar de la distancia que las separa, es especialmente destacable el estrecho parecido con el grupo de las diosas preñadas de la vegetación, definido por M. Gimbutas en la zona de los Balcanes. Estas se manifiestan en la representación naturalista de una mujer embarazada con las manos descansando por encima del vientre y entronizada o sentada. Dicha divinidad es, según M. Gimbutas, una adición particular del Neolítico al panteón de las prehistóricas, que simboliza la fertilidad de la tierra, respuesta natural en una forma de vida agrícola. Los mejores ejemplos incluyen la Dama de Kökénydomb (SE de Hungría) que tiene forma de vaso, y la Dama de Pazardzik (centro de Bulgaria) (Kalicz, 1970: fig. 36; Gimbutas, 1991: 240-243, fig. 207-211).

En un primer orden de cosas la Venus de Gavà es un importante dato que se suma a los que sugieren una vinculación entre la cultura Chasense del norte de los Pirineos y la de los Sepulcros de Fosa de Cataluña. Ya hemos citado las figuras femeninas del Neolítico Medio francés, pero es en el esgrafiado sobre la superficie bruñida de la cerámica, en particular utilizado para el diseño de motivos solares, donde pueden encontrarse los paralelos más estrechos.

El motivo solar esgrafiado sobre cerámica bruñida, al parecer, pertenece específicamente a la cultura Chasense, aunque establecer una cronología en base a él es aún imposible (Paccard, 1988: 196). Aparece en Villeneuve Tolosane (Alto Garona), representado en el centro de la base interna de una copa (Vaquer, 1990: 262, fig. 136.2). Un recipiente cerámico con decoración solar procede del abrigo 4 de Fraischamp (La Roque-sur-Pernes). Se trata de un fragmento con decoración esgrafiada posterior a la cocción, compuesta por tres soles completos de forma ovoide (Paccard, 1988: 195, fig.3). Otros ejemplos de decoraciones solares son los de la cueva de Vidauque à Cheval-Blanc (Courtin, 1974), el de Escanin (Montjardin, 1966), los de Lattes (Mendoza Prades, 1988: fig. 7.1 y 13.10). En Cataluña conocemos únicamente las decoraciones soliformes esgrafiadas sobre dos fragmentos de cerámica que corresponden al mismo yacimiento de las Minas Prehistóricas de Gavà (Villalba et alii, 1992: 225, fig. 2.7 y 2.8. Excavaciones inéditas de Bosch, Cuesta y Arenas). 
Por lo que se refiere al significado de la Venus de Gavà, desde nuestro punto de vista puede interpretarse como figura antropomorfa femenina. Esto se deduce de la representación de los pechos, del abdomen abultado y de la posible vulva en forma de espiga invertida. Así mismo, creemos que puede relacionarse con la estructura ideológica de las sociedades neolíticas de Gavà.

Son aceptadas las prácticas religiosas en el Neolítico, sin embargo es poco abundante la documentación al respecto, especialmente en ia Europa occidental. Por otro lado, los escasos ejemplos de objetos supuestamente relacionados con dichas prácticas (estatuillas, probablemente copas con pie y objetos diversos) no parecen, dada su repartición geográfica muy contrastada, traducir un ejercicio religioso regular ni una preocupación continuada por lo sobrenatural.

El descubrimiento de figuritas femeninas (embarazadas o con los caracteres sexuales acentuados), relativamente similares en yacimientos distantes, ha inspirado una tradición erudita sobre una religión prehistórica generalizada basada en el culto a la diosa madre y a la fecundidad. Si bien éste debió ser, junto al de los muertos, uno de los principales cultos del Neolítico, éstos pudieron abarcar otros muchos aspectos y diferir radicalmente de unas sociedades a otras. No estando demostrada la primacía de la diosa madre. Por otro lado un mismo objeto u objetos similares pudieron tener significados diferentes. Así mismo, su asociación mayoritaria a un contexto no ritual, sugiere una religiosidad sin un principio unificado.

En el caso de la Venus de Gavà, y a pesar de la distancia que las separa, el estrecho parecido con las citadas diosas preñadas de la vegetación, definido como hemos visto por M. Gimbutas en la zona de los Balcanes, creemos que hace muy probable su vinculación a cultos a la fertilidad. Ahora bien, es posible que esta fertilidad hayamos de entenderla no únicamente en un sentido agrícola, sino en uno más ámplio que incluya también la fertilidad mineral de la tierra. El hecho de haber encontrado la figurita de Gavà en el interior de una mina y correspondiendo a una comunidad de mineros lo sugiere.

Los miembros de las sociedades neolíticas de Gavà no debieron ser los únicos mineros en adoptar un culto inicialmente agrícola. En las minas de Grimes Graves (Norfolk, Gran Bre- taña) una presunta diosa de la fertilidad ejecutada sobre yeso fue encontrada en el fondo de uno de los pozos. La interpretación dada a este hecho por algunos de los arqueólogos que habían estudiado las citadas minas es la de que fue llevada y depositada allí con el fin de realizar una ceremonia ritual, asociada al trabajo minero, quizás para pedir bien una mayor calidad y cantidad en el sílex extraído en el próximo pozo, o bien buena suerte para librarse de posibles accidentes (Green, 1993). Más moderno, y de carácter etnográfico, es el ejemplo de los indios quéchuas bolivianos. Los mineros de este pueblo practican, como los agricultores, un culto a la diosa Pacha Mama (madre tierra).

Un último aspecto queremos comentar en relación con el significado que pudo tener la Venus de Gavà. Al igual que otras muchas estatuillas neolíticas, ha aparecido rota y con una dispersión de los fragmentos difícil de interpre$\operatorname{tar} y$, dado el caracter cerrado del lugar en el que fue hallada (interior de una mina), no justificable por alteraciones postdeposicionales. Una posible explicación es que en ocasiones la plástica neolítica tuviese funciones limitadas.y momentáneas. Su ayuda solamente sería necesaria unos días precisos, durante acontecimientos importantes o en la ejecución de determinados trabajos. Una vez finalizados éstos o alcanzado el objetivo, las figuritas perderían su contenido y significación (Srejovic, 1968).

Finalmente, y una vez considerados los ejemplos de figuras neolíticas recogidos en este artículo, podemos comprobar que la Venus de Gavà es la primera figura claramente antropomorfa conocida para el Neolítico de la Península Ibérica. Es la más completa, de mejor calidad y mayor detalle en la figuración de la Europa occidental. Su morfología general y la presencia de determinados motivos decorativos permiten suponerle un valor simbólico y religioso, y empezar a considerar con una cierta base la existencia entre las sociedades del Neolítico Medio del occidente europeo de unas prácticas religiosas centradas en el culto a la diosa madre o a la fertilidad. 


\section{BIBLIOGRAFÍA}

ÅBERG, N. (1921): "La civilisation néolithique dans la Peninsule Iberique". Librairie Ancienne. Paris.

BAGOLINI, B. (1978): "Le immagini femminili nell'arte neolitica dell'Italia Settentrionale". A L'arte prehistorica nell'Italia settentrionale dalle origini alla civiiltà paleoveneta. Museu Civico di Storia Naturale. Verona: 4147.

BarandiarÁn, I. (1978): "El abrigo de la Botiquería dels Moros. Mazaleón (Teruel). Excavaciones arqueológicas de 1974". Cuadernos de Prehistoria y Arqueología Castellonense, 5: 49-138.

BORDREUIL, M. (1993): "Recherches sur les rélations entre les statues menhirs et les céramiques, armes, outils et parures contemporains, dans les habitats et les sépultures du Languedoc Oriental”. En A.J. Briard y A. Duval A. (dirs.): "Les répresentations humaines du Néolithique a l'Age du Fer". Actes del $115^{\mathrm{e}}$ Congrès National des Sociétés Savantes. CTHS: 71-75. Paris.

Bosch, J. (1991): "El Neolític Antic al Vallès Oriental". Arraona, 8: 9-32.

Bosch, J. y Estrada, A. (en premsa): "El Neolític Postcardial a les Mines Prehistòriques de Gavà (Baix Llobregat, Barcelona)". Rubricatum, revista científica del Museo de Gavà.

CAuvin, J. (1972): "Religions néolithiques de Syrio-Palestine". Publications du Centre de Recherches d'Ecologie et de Prehistoire. Librairie d'Amerique et d'Orient. Paris.

Chapman, R. (1991): "La formación de las sociedades complejas. El sureste de la península ibérica en el marco del Mediterráneo occidental”. Editorial Crítica. Barcelona.

Clottes, J, y CARriere, M. (1974-76): "La Statue féminine de Capdenac-le-Haut (Lot)". Congrès Préhistoire de France, $X X^{e}$ Session, Provence: 102-108.

Courtin, J. (1974): Le Néolithique de la Provence. Mémoires de la S.P.F., 11.

Garasanin, D. (1968): "Croyances et culte de l'homme néolithique dans le centre des Balkans". A Les regions centrales des Balkans à l'époque Néolithique. Musée National. Belgrad: 25-29.

GimbutAS, M. (1989): "The language of the Goddes". Thames and Hudson. San Francisco. (1991): "Diosas y Dioses de la Vieja Europa 7000-3500 a.C.: mitos, leyendas e imaginería". Ed. Istmo. Madrid.

Green, B. (1993): "Grime's Graves. Norfolk”. English Heritage. Londres.

GuILAINE, J. (1980): "La France d'avant la France". Hachette. Paris.

KaliCZ, N. (1970): "Dieux d'argile. L'Age de pierre et de cuivre en Hongrie". Hereditas, Ed. Corvina. Budapest.

KOZLOWSKI, J.K. (1990): "Le complexe impresso-cardial et les civilisations Balkano-danubiennes au sud des Al- pes". A D. Cahen et M. Otte (eds.): "Rubané et Cardial". Actes du Colloque de Liège, 1988. Etudes et Recherhces Archéologiques de l'Université de Liège, 39: 65-72. Liège.

MARTi, B. (1990): "El neolítico". En "Historia de España". Editorial Planeta. Barcelona: 149-232.

Mendoza, A. \& Prades, H. (1988): "Le gisement chasséen de Lattes". A Le Chasseen en Languedoc Oriental. Hommage à Jean Arnal. Actes des Journées d'Etudes (Montpellier, 1985). Université de Montpellier: 83-104.

MontJardin, R. (1966): "Le gisement d'Escanin aux Baux-en-Provence”. Cahiers rhodaniens, XIII: 5-100.

MONTJARDIN, R. Y Roger, J.M. (1993): "Les figurations anthropomorphes, zoomorphes ou végetales du néolithique ancien au bronze final dans le midi méditerranéen". A.J. Briard y A. Duval (dirs.): Les répresentations humaines du Néolithique a l'Age du Fer". Actes del $115^{\mathrm{e}}$ Congrès National des Sociétés Savantes. CTHS. 85-106. Paris.

PACCARD, M. (1988): "Un decor solaire chasséen en Vaucluse". A Le Chasseen en Languedoc Oriental. Hommage à Jean Arnal. Actes des Journées d'Etudes (Montpellier, 1985). Université de Montpellier: 193196.

RoMero, V. y Miro, J.M". (1993): "Datació per C14 de l'esquelet femení de la Timba del Barenys". Lo Floc, Revista del Centre d'Estudis riudomencs Arnau de Palomar: 6.

SRejovic, D. (1968): "La plastique néolithique de la Région Balkanique centrale". A Les regions centrales des Balkans à l'époque Néolithique. Musée National. Belgrad: $19-24$.

VAQUER, J. (1975): "La céramique chasséenne du Languedoc". Atacina, 8. Carcassonne.

- (1990): "Le Néolithique en Languedoc Occidental". Ed. CNRS. Paris.

VILARDELL, R. (1992): "Problemàtica que ens planteja la troballa d'una inhumació a la Timba d'En Barenys (Riudoms, Baix Camp)". gè Col.loqui Internacional d'Arqueologia de Puigcerdà. Estat de la investigació sobre el neolític a Catalunya (Puigcerdà-Andorra, 1991): 117-118.

Villalba, M.J.; Bañolas, L. ; Arenas, J. y Alonso, M. (1986): "Les mines neolítiques de Can Tintorer, Gavà. Excavacions 1978-1980". Departament de Cultura. Generalitat de Catalunya. Barcelona.

Villalba, M.J.; BAÑolas, L. Y Edo, M. (1992): "Les ceràmiques decorades del complex miner de Can Tintorer relacionables amb les del Chassià meridional clàssic". gè Col.loqui Internacional d'Arqueologia de Puigcerdà. Estat de la investigació sobre el neolític a Catalunya (Puigcerdà-Andorra, 1991): 223-227. 